\title{
A preliminary study on the course system of flight principle numerical experiment
}

\author{
Guangxu Ren ${ }^{1, a}$, Xiujuan $\mathrm{Liu}^{2, \mathrm{a}}$, TieYu Hu \\ Aviation University of Air Force \\ Changchun, China \\ 723704537@qq.com
}

\begin{abstract}
Keywords: Flight principle course; numerical experiment; knowledge system; teaching mode
\end{abstract}
\begin{abstract}
In this paper, a preliminary study on the knowledge system and teaching model of numerical experiment is made for the flight principle course. In this paper, the flight principle professional numerical experiment course is divided into four levels: flight theory, numerical calculation knowledge, numerical software and the development and application of some of the levels, and puts forward the numerical experiments throughout the flight teaching process, and the curriculum design organic combination and laboratory to students open teaching mode, in order to improve the teaching quality, enhance students' ability to think independently, to cultivate innovative spirit and improve the comprehensive quality.
\end{abstract}

\section{Introduction}

Numerical experiment course training students' experimental ability, stimulate students' desire to explore knowledge is an important link to improve students' comprehensive quality and cultivate innovative spirit, with other teaching forms can not replace the important role, has become the important part of the teaching of flight principle.

The numerical experiment course of flight principle is still at the beginning stage in our school. The basic problems such as course system, teaching mode and so on have yet to be studied. At the same time, because of the importance of numerical experiment teaching is not enough, there are different degrees of the basic theory of numerical value, or ignore the practice of the phenomenon. Therefore, it is necessary to sort out the knowledge structure of the numerical experiment course, and study the teaching mode of the numerical experiment in the different stages of the flight principle.

The significance of setting up numerical experiment course. Numerical experiment series courses, not only can make up for the shortcomings of the conventional experimental conditions, enhance students' perceptual knowledge and learning interest, improve teaching effect, but also can reproduce the known phenomena through numerical experiments, deepen the understanding of the actual test of the observed phenomena, training students hands-on ability and innovative consciousness, the teaching of our school, research and development has a very important practical significance.

To make up for the deficiency of conventional experiment teaching. In flight principle, the basic theoretical knowledge and laboratory experiments are complementary to each other, which is an important part of the teaching of flight principle. At present, due to various reasons, we have to cut down many teaching experimental items. We can only show the basic experiment and a small number of elective experiments. The way in helping students to further understand the teaching content at the same time, but in varying degrees to stifle the students' ability to analyze and solve problems, but also easy to make the students to produce one-sided or even wrong understanding. The condition of numerical experiment is simple, students can easily reproduce laboratory experiments with the help of teachers, which makes up the deficiency of the conventional experiment teaching. 
The flight principle of practice teaching system generally include the content of the laboratory, specializes in the room, and teaching resources construction, as shown in the following illustration, numerical experiments are mainly reflected in the first module.

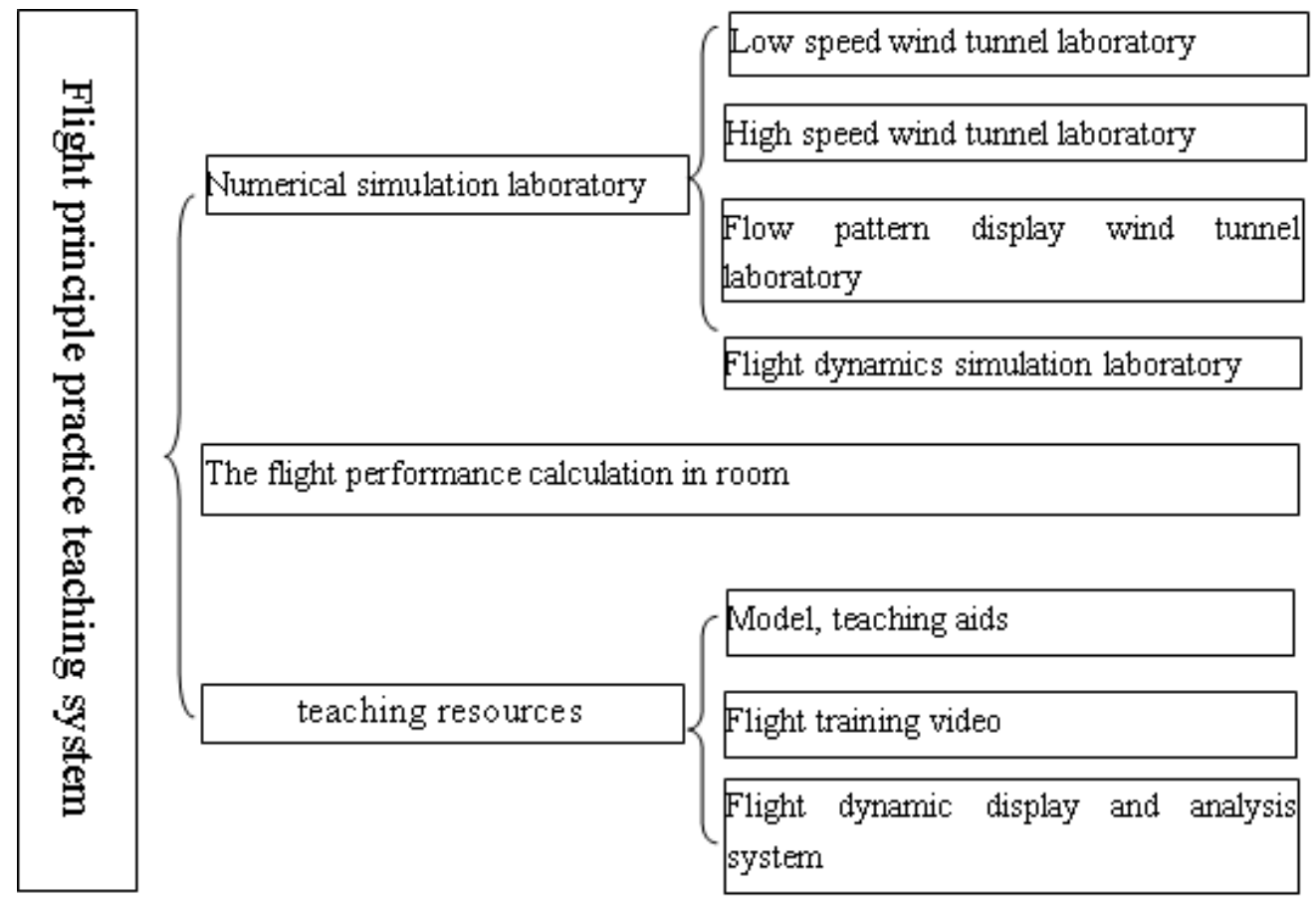

Improving the effect of experiment teaching of flight principle.Through a variety of means to reproduce the known phenomenon, deepen the interpretation of the observed phenomena observed in the experiment, and get a lot of important information in the actual test room is not observed. For example, using FLUENT software to simulate the flow of air flow through the airfoil surface experiments, the basic retention of the intuitive nature of the advantages, can reproduce the laboratory experiments observed including the attached surface layer separation, the head shock, leading edge shock and other phenomena, deepen the student's impression. At the same time, it can also adjust the wind speed and the angle of the airfoil, to help students understand the basic concepts and the basic concepts of shock and so on.

To cultivate students' ability to practice and innovate.With the development of the subject, some new experimental methods and experimental techniques have been developed, which requires the continuous updating and improvement of the experimental equipment. But the development of our school's laboratory is relatively backward, and the traditional experiment mode is very difficult to keep up with the development of the subject, and the numerical experiment can make up for this problem.

Flight theory teaching, students master the numerical simulation of basic skills can further on some due to the objective conditions do not offer or is difficult to open the laboratory experiments, and even cutting-edge academic issues of numerical experiments, such as high speed airfoil wind tunnel blow wind experiment, liquid display wind tunnel experiment, water tunnel experiment, to achieve students hands-on ability and innovative consciousness of teaching objective, and to provide a practical solution to the problem in their future study and work.

Constructing the knowledge system of numerical experiment course.As an important research method, numerical simulation experiment has been an essential skill for scientific research, and it has been widely used in production practice in various fields. In order to make the theory of flight professional students in the theoretical education of the basic theory of numerical simulation, the knowledge system of numerical experiments can be divided into four levels, the basic knowledge of flight theory, numerical computing knowledge, numerical software and the development and application of the four levels, the number of values of the experimental knowledge system is closely related, should not be divided. 
Basic knowledge of flight theory is an important foundation of the knowledge system of numerical experiment course. Using numerical (experimental) method for students engaged in scientific research and learning theory provides an important tool or skills to solve practical problems is the ultimate goal, which is to simulate a conventional flight principle experiment, or simulation of a complex engineering problems involved in the model dimensions, boundary conditions, material properties, and simulation results verify and analysis are not separated from the corresponding flight principles of knowledge system, content characteristics, the design of the experimental project and content is the key and core. The basic knowledge of a solid, broad flight principle is a student or a person who is interested in engaging in numerical research.

Numerical knowledge is the necessary content of the knowledge system of numerical experiment course.A good numerical experiment should be based on the characteristics of the specific problem, in the right to choose and use the appropriate algorithm based on the. This requires the students to choose the appropriate language programming or two development of the corresponding algorithm, and the convergence of the algorithm itself, stability and error estimation and other basic knowledge necessary to understand. Therefore, only to read and make good use of FORTRAN language, C language, numerical calculation method and other numerical knowledge, in order to lay an important foundation for the numerical experiment curriculum knowledge system.

Numerical software is the core part of the knowledge system of numerical experiment course.In the completion of the classroom teaching tasks, teachers have a sense for students to introduce the use of FLUENT, ANSYS, RFPA, UDEC, MATLAB and other numerical software, complete a variety of basic numerical experiments, to master the basic process and skills, can improve students' knowledge of the relevant flight principles and the finite element method of perceptual knowledge for students to learn and work in the future to provide a practical solution to the problem. Therefore, understanding and preliminary grasp of numerical software, is the core of the students to master the skills of numerical experiments.

The development and application part is the important development of the knowledge system of numerical experiment course.Part of the students' graduation design and part of the curriculum design and even in the future of flight practice will be different degrees of numerical experiments, some of the comprehensive analysis of the problem. These teaching links, students need to master a variety of ways to master a certain number of experimental technology, comprehensive use of knowledge of the first course of repair, more skilled application, and even the appropriate development of numerical software two times, complete the teaching task. Through these teaching process, we can train students to analyze and solve the problem of flight, the ability of the actual problem in engineering.

Teaching model of numerical experiment course.At present, there are a lot of problems in the teaching of aviation, which lack of learning enthusiasm and initiative, innovative awareness and ability is not strong is the main performance of the student level, flight course is also the same. In order to change this situation, try to reform the teaching mode, and put the numerical experiment through the whole teaching process in order to improve the teaching effect.

Combining the teaching of flight principle with the computer numerical simulation, the teaching content of the experiment course is added, and the students' interest in exploring science is stimulated. On the basis of the theory, strong flight principle basic knowledge in the course of some of the more difficult to understand, relatively boring content, through language description or conventional teaching methods to the performance of the content, such as the generation and development process of the transonic flow characteristics and shock wave, you can through animated display the results of numerical experiments, and by changing the the relevant parameters of numerical experiments in the process, will have different results, so easily lead to students' thinking and discussion, through the creation of similar design, open experiment content and projects, to a large extent can make the past theory teaching more interesting and dull as ditch water, it can not only supplement the experimental teaching, and can enhance students' perceptual understanding of the principle of flight theory, inspire students interested in exploring the mysteries of science. 
The flight principle numerical experiment teaching and case teaching organic combination, enhance student's study enthusiasm, train the student's creative thinking ability. In the numerical software, the flight case discussion and verification methods into the experiment, such as in the daily flight will often encounter some special situations, we study these special circumstances, as a result of the accident can not be repeated, difficult, for accident investigation principle at this time, we can use the related parameters of the actual acquisition of flight in numerical simulation, so as to realize the truth, to find the cause of the accident, to avoid similar accidents and provide a theoretical basis to solve, through such actual case analysis, and promote the ability of student theory with practical problems, which greatly mobilized the enthusiasm and initiative of student learning, enhance participation the consciousness of students, to stimulate the enthusiasm of students, and enrich the course content.

The combination of numerical experiments and curriculum design, cultivate students' ability to solve practical problems, and enhance the comprehensive quality of the students. Technology and methods to master, the ultimate goal is to have the ability to form after training, so in teaching to provide students with mobile phones, to build a practical platform. We can use the curriculum design, graduation design and the various innovation competitions organized by the school and classroom teaching and second classroom activities, to encourage students to actively participate in the introduction of other areas of the actual and cutting-edge technology development research in the case, for students to collect the relevant issues of typical materials, and then to discuss and provide solutions for students to solve practical problems by numerical experiments. Combined with open laboratory and other measures to comprehensively improve students' ability to think independently, to solve the problem of the ability to solve problems and innovative spirit and comprehensive quality.

\section{Summary}

Because of the great effect of numerical experiment in teaching and scientific research, the numerical experiment course has been paid more and more attention by the teachers and students. However, the knowledge system and teaching model of numerical experiment still need to be innovative and perfect in practice. In addition, the selection and design of basic, comprehensive and applied numerical experiment content, teachers' quality and ability are also need to do a lot of work in order to meet the needs of flight students to numerical experiment teaching.

\section{Reference}

[1] Yang Xiaojing, Ji Cheng rang, Zhang Min. Several suggestions to improve the teaching quality of college physics experiment [J]. university physics experiment, 2009, 22 (2): 106-108

[2] Xu Gang. Study on the reform of college physics experiment teaching [J]. university education research, 2009 (6): 17

[3] Ouyang Kui, Li Shaozhong. Current situation and Reform Strategies of experimental teaching of basic courses of computer application in Higher Vocational Colleges [J]. China Vocational and technical education, 2011 (2): 28 - 31

[4] Song Jinfan, Zhang Ping, Xu Hairu. Research on the cultivation of physics experiment teaching and innovation ability [J]. laboratory science, 2010 (2): 25-27

[5] He Lefan. Principle of modern education. Science Press, 1988

[6] Guo Jiuling. The charm of teaching. Peking University press, 2010.1 